\title{
PARA ALÉM DO 'TRÂNSFUGA DE CLASSE' A socialização plural em narrativas da primeira geraçáo de formados no ensino superior
}

\section{Raquel Guilherme de Lima (1)}

(D) https://orcid.org/0000-0002-0253-9144

(1) Departamento de Sociologia e Metodologia das Ciências Sociais (GSO) - Universidade Federal Fluminense (UFF), Niterói - RJ, Brasil.

E-mail: raquel.guilherme@gmail.com

DOI: $10.1590 / 3510414 / 2020$

\section{Introdução}

A relação entre desigualdades sociais e educacionais tornou-se um dos objetos de pesquisa mais explorados na área da Sociologia da Educação, a partir da década de 1960. Contrapondo-se a um período de otimismo em relação ao papel da instituição escolar nas sociedades ocidentais, devido à então hegemonia de teorias da modernização com forte acento funcionalista, a demonstração de que o alcance educacional dos indivíduos estava condicionado às suas características de origem foi um importante resultado para o avanço da produção científica na área.

Se há muito sabemos da tendência à reprodução social no sistema escolar, é notório também que, mesmo ante tal imperativo, membros das camadas populares, ainda que poucos, triunfam nesse ambiente adverso.

Artigo recebido em: $17 / 10 / 2018$

Aprovado em: 22/01/2020
Casos como estes foram e são motivo de inúmeras investigaçôes sociológicas, na tentativa de compreender como percursos considerados improváveis - ou seja, casos de sucesso escolar das camadas populares - tornaram-se possíveis. Nas últimas décadas, a excepcionalidade destas trajetórias vem sendo moderada, em virtude da forte expansão educacional observada em diversos países, em meados do século XX, aumentando as oportunidades para grupos subrepresentados acessarem as instituiçóes escolares e permanecerem nelas até os níveis mais avançados. Contudo, mesmo com a expansão de oportunidades educacionais, concluir um curso superior ainda é um desafio para sujeitos vinculados às identidades e às condiçóes sociais que impóem barreiras persistentes ao êxito nos estudos (Shavit, Blossefeld, 1991).

Tardiamente, em comparação com outros países da regiâo, como, por exemplo, o Chile e a Argentina, o Brasil também aumentou substantivamente a cobertura do seu sistema educacional, em período 
recente. No final dos anos 1990, alcançamos a universalizaçáo do ensino fundamental e, nos anos subsequentes, testemunhamos o crescimento do número de matriculados no ensino médio e na educação superior (Ribeiro, Marschner \& Ceneviva, 2015). O presente artigo investiga uma dimensão das consequências da recente expansão educacional ocorrida no sistema de educação superior. Através da análise qualitativa das narrativas de egressos da educação superior, oriundos das camadas populares, argumenta-se sobre os impactos dessa trajetória na percepção de mundo e na sociabilidade destes sujeitos.

$\mathrm{O}$ objeto de análise que motiva esta discussão reside, portanto, nas narrativas de egressos do sistema de educação superior classificados como pertencentes às camadas populares, devido a características educacionais e ocupacionais de seus pais. A discussão proposta questiona as interpretaçóes que abordam o tema da adaptação à nova experiência exclusivamente através da chave do conflito e que, por isso, ressaltam o sofrimento que acometeria a primeira geração de formados na educação superior, como consequência de um sentimento de desajuste ao novo ambiente, muitas vezes, descrito como estranho e hostil. Outra consequência da mobilidade educacional do referido grupo, também interpretada como fonte de conflito, é a mudança no padrão de relaçóes sociais do indivíduo, percebida como afastamento de sua origem.

Como hipótese a ser trabalhada, propóe-se, neste artigo, que tais interpretaçôes privilegiam a chave do sofrimento e do desenraizamento como consequência da adesão teórica ao conceito de trânsfuga de classe, elaborado por Pierre Bourdieu (2008, 2011). Em contraponto ao uso desse conceito, o estudo aqui apresentado mobiliza a crítica de Bernard Lahire (2002, 2006) a modelos unívocos de socialização, que pressupóem a formação de um único repertório de açóes baseado no pertencimento de classe do agente. A intenção do presente artigo não consiste em negar as dimensóes conflituosas vivenciadas no processo de mobilidade educacional, mas sim demonstrar como membros das classes populares podem ter acesso a experiências que os habilitem a navegar no ambiente universitário com maior facilidade, apesar das dificuldades impostas pela desigualdade social. Aspectos relacionados à sociabilidade dos entrevistados também são examinados para argumentar contra interpretaçóes de deserção, desenraizamento ou desajuste.

Ressalta-se, dessa forma, a importância de melhor compreender experiências de mobilidade educacional vivenciadas no sistema brasileiro de educação superior, especialmente em um momento em que se observa uma série de resultados da recente expansão de vagas e, também, da introdução de mecanismos de democratização do acesso. Estudantes de origem popular, negros e representantes de minorias, embora já circulassem nas universidades e faculdades brasileiras, são agora mais numerosos, em comparação às décadas pregressas. Além do potencial analítico que os casos revelam, é necessário conhecer os meandros das trajetórias desses sujeitos, por diferentes ângulos, para a formulação e adequação de políticas públicas que visem não apenas ao acesso deste público, mas também à sua permanência com qualidade, nestas instituições.

O debate teórico apresentado dialogará com a análise de dados obtidos através de entrevistas em profundidade, realizadas com um grupo de 25 pessoas de origem popular, consideradas como a primeira geraçáo de suas famílias a obter o diploma superior. O ponto específico é problematizar a imagem comumentemente atribuída a estas trajetórias populares na educação superior, ressaltando, como já dito, o seu sofrimento, o sentimento de não pertencimento e a ruptura cultural com o meio de origem. Sem a pretensão de apresentar uma revisão exaustiva, busca-se, aqui, dialogar com importantes contribuiçóes na academia brasileira e com outros exemplares da produção internacional que abordaram especificamente tal aspecto. A partir desse debate, são questionados os ganhos analíticos que a mobilizaçáo do conceito de trânsfuga de classe traria para a compreensão destes casos de mobilidade educacional, uma vez que a ênfase no desajuste social, que a experiência no sistema de ensino superior supostamente representaria para estas pessoas, é em parte devedora do uso deste conceito.

$\mathrm{O}$ artigo está organizado em quatro seções, além desta introdução. Na primeira seção, o debate teórico é construído a partir do diálogo com trabalhos da área, que abordam a mobilidade educacional ressal tando os conflitos e desajustes decorrentes dessa experiência. 
Logo em seguida, são apresentados a metodologia e o material empírico utilizados para responder ao problema proposto. $\mathrm{Na}$ terceira seção, o material empírico é articulado aos argumentos centrais do artigo. Por último, as consideraçôes finais pontuam as conclusôes e a contribuição que o trabalho pretende oferecer ao debate.

\section{Casos improváveis na educação superior: os dilemas e sofrimentos de um trânsfuga}

Mesmo após a queda histórica da desigualdade social, registrada na última década, as distâncias que separam as classes sociais no Brasil contemporâneo ainda são bastantes significativas (Carvalhaes, Ribeiro, Souza \& Barbosa, 2014). Distâncias estas, que tornam compreensíveis as frequentes interpretaçôes de histórias de ascensão social, que partem dos meios populares, como um movimento cercado de choques culturais e tensôes em busca de adaptação ao novo meio. Sem dúvida, como coloca Pierre Bourdieu, "ir de baixo para cima é guindar-se, trepar e trazer as marcas ou os estigmas desse esforço". (Bourdieu, 2007, p. 137). Este é o caso das trajetórias de mobilidade educacional na educação superior brasileira, retratadas, na maior parte das vezes, como um movimento difícil e que guarda em si um enorme desgaste pessoal. Obstáculos diversos - como a necessidade de conciliar estudo e trabalho; a deficiência dos conteúdos ensinados; as longas distâncias percorridas entre a casa, o emprego e a universidade - foram bem documentados pela literatura (Portes, 1993, 2001; Viana, 2007; Almeida, 2012; Silva, 2011; Piotto, 2007, 2008, 2010). Outro conjunto de fatores relacionado a tais dificuldades, mas não ocasionado unicamente por elas, e frequentemente citado nesses estudos, refere-se aos impactos psicossociais provocados pela mobilidade educacional vivida no ensino superior. Sentimentos de solidão, não pertencimento e deslocamento são mencionados como efeitos colaterais de "subir na vida" e enfrentar ambientes distintos daqueles habituais. Alguns trabalhos aprofundam essa dimensão, a partir da análise dos efeitos que a entrada na universidade acarretam para o estudante e sua família, e, desse modo, deslocam a atenção para as demais relações que o indivíduo estabelece (Viana, 2007; Piotto, 2007).
Nas pesquisas consultadas, tal questão muitas vezes se sobressai, quando o assunto é a adaptação ao meio universitário do estudante originário de estratos sociais em que o diploma de nível superior é um distintivo raro. Contribuiçóes, como a de Viana (2007) e Portes (2001), afirmam que a travessia dos jovens universitários entre os dois mundos, o de origem popular e o novo mundo representado pela formação superior, não é feita sem enorme desgaste pessoal. Portes (2001), contudo, disserta sobre esse desgaste em termos ambíguos, ao pontuar a entrada na universidade vivida como um choque cultural para os sujeitos investigados, mas também como uma abertura para novas experiências e aprendizagens. O foco do autor se encontra na vivência universitária de seus investigados e em suas estratégias de adaptação a tal ambiente. Já Viana (2007) desloca a atenção para além dos muros da universidade, pontuando os custos subjetivos com que o indivíduo tem que lidar ao transitar entre dois mundos distintos. Consciente das ambiguidades que podem envolver esse trânsito, a autora considera a hipótese de que as trajetórias possam ser marcadas tanto por relaçóes de ruptura, quanto de continuidade com a origem popular, valorizando, assim, a dimensão do conflito entre os dois ambientes sociais nos quais o indivíduo se insere após sua aprovação no vestibular: "[...] não se vive impunemente o fenômeno do distanciamento cultural das origens, seja pela sua resultante - a de transformar-se em trânsfuga - seja pela própria experiência do processo". (Viana, 2007, p. 239). Com menor ênfase, mas atento a esse importante aspecto da ascensão social vivida por seus investigados, a análise de Silva (2011) das trajetórias universitárias de moradores do Complexo de Favelas da Maré, no Rio de Janeiro, nos informa que somente em um caso houve, mais destacadamente, a percepção de desenraizamento do meio de origem após a experiência universitária. Nesse trabalho, há o relato de um enorme desconforto sentido pela entrevistada, entre o modo de vida representado pela origem social e aquele adquirido após a graduação. Buscando um contraponto mais contundente às teses de desenraizamento, conflito e ruptura com a origem, Piotto (2007) argumenta que a experiência vivida pelos jovens de origem popular na universidade não representa necessariamente uma 
cisão com o seu repertório cultural de origem, mas sim uma nova experiência enriquecedora, que se soma às demais preexistentes. A autora ressalta, ainda, que o sofrimento não é o principal tom dos relatos obtidos, mesmo que ele esteja presente nas mençóes às dificuldades vividas durante a trajetória universitária, no que se refere às desigualdades socioeconômicas.

De acordo com Jules Naudet (2007), a experiência de mover-se entre estratos sociais distintos, perfazendo um caminho de ascensão social, é comumentemente retratada a partir de dois extremos. De um lado, teríamos um sujeito atormentado pela dissonância encontrada entre os dois mundos; de outro, a imagem de alguém que abandona suas origens e assimila totalmente os valores da classe de destino. Em concordância com o argumento de Naudet (2007), é necessário, a partir do estudo de casos de ascensão social, problematizar essas abordagens extremas que ora descrevem um processo de anomia, corporificado em um sujeito completamente desajustado, ora apontam para um sujeito "aculturado", que rejeita suas raízes em favor do novo. Sujeitos em permanente conflito e angústia compóem a caricatura que se desprende de parte das investigaçóes sobre trajetórias educacionais longevas nas camadas populares. Este retrato é obtido, em sua maioria, como consequência da lente teórica mobilizada para interpretar os achados empíricos alicerçadas sobretudo na tradição disposicionalista da ação - abordagem, por excelência, vinculada à contribuição teórica metodológica de Pierre Bourdieu.

O trânsfuga de classe, em referência àquele que deserta de suas origens, é o conceito comumente acionado para representar tal movimento. O conceito carrega um sentido negativo, o de deserção, atribuído à experiência de mover-se entre estratos sociais distintos, perfazendo um caminho de ascensão social. Originalmente, o termo foi utilizado para descrever movimentos radicais de ascensão social, o que não contempla os casos aqui analisados. A saída da classe trabalhadora para a ocupação de uma posição de classe média, destino comum para a maioria dos jovens adultos que compóem o grupo investigado, também é, entretanto, interpretada e analisada sob a influência do referido conceito em grande parte da literatura consultada.
$\mathrm{Na}$ obra de Pierre Bourdieu, encontramos o exemplo do trânsfuga de classe, compreendido através de distintas chaves. $\mathrm{O}$ aculturamento do pequeno burguês, descrito no livro $A$ Distinção, revela um padrão de total deserção e negação das disposiçôes adquiridas na socialização primária: "A decolagem sempre supõe uma ruptura, cuja negação dos antigos companheiros de infortúnio representa apenas um aspecto. Exige-se que o trânsfuga vire a mesa dos valores, proceda a uma conversão de toda a sua atitude". (Bourdieu, 2011, p.316). No texto As Contradiçóes da Herança, a ênfase está na enorme culpa que acomete quem melhora de vida, embora oriundo das classes subalternas. "...tenha sucesso, mude, torne-se um burguês, e permaneça simples, sem altivez, perto do povo...” (Bourdieu, 2008, p.590): o pedido inconsciente do pai que deseja a ascensão social do filho, mas teme que este movimento acabe por separá-los em mundos distintos, é o reflexo máximo do êxito vivido como fracasso. Aqui, não há a mesquinhez do pequeno burguês, envolto nos seus cálculos de grandeza, a ignorar o que for preciso para atingir o seu objetivo. O personagem atormentado pela culpa é o que não consegue instrumentalizar completamente as suas relaçôes pessoais e valores em favor de seu projeto de ascensão. Numa perspectiva autobiográfica, Bourdieu redime apenas o intelectual de origem humilde, que, a partir de uma autorreflexão sobre a própria trajetória, pode apaziguar tamanho conflito.

Autores amplamente citados na produção brasileira sobre educação e classe trabalhadora, Richard Hoggart (1973) e Jean Claude Terrail (1990) também expóem os dilemas da ascensão social via educação, mobilizando a imagem do trânsfuga de classe.

Nos dois volumes dedicados à discussão da vida cultural da classe trabalhadora, Richard Hoggart (1973) descreve o modo de vida do proletariado inglês, do início do século XX até o final dos anos 1950. Baseado em reflexóes autobiográficas, o ambiente descrito nos remete a um contexto de forte reprodução social amparada no cultivo e na valorização de certo conformismo e resignação com a própria condição. O ambiente homogêneo e totalizante, contudo, não impede que dele se encontre a possibilidade de saída. O bem-aventurado, que consegue melhorar de vida, não é, por isso, excluído ou estigmatizado pelo grupo 
de origem. A interdição, dessa forma, não é feita à ascensão social, mas ao questionamento que práticas e valores do universo proletário possam sofrer por quem experimenta outras influências: "Comportamentos classificados como não conformes às ideias do grupo 'dar-se-ares', 'ter a mania que é superior' [...] são reprovados e duramente sancionados". (Hoggart, 1973, p. 104).

A busca de uma vida mais afluente, tolerada pelos pares, não é, contudo, fácil de assimilar, uma vez tornada realidade. A ascensão através da educação, vivida pelo próprio Hoggart, é o exemplo em que ele se baseia para descrever o desenraizamento social do jovem proletário que toma esse caminho. A chave aqui é a de uma deserção não intencionada, mas inevitável, quando se adquire outro status social a partir do diploma. A escalada do jovem proletário é representada por um calvário, no qual ele se sente irremediavelmente distante dos pares, ao mesmo tempo em que adentra um ambiente hostil que lhe demanda enorme esforço para decifrá-lo.

O trânsfuga de classe também é a imagem escolhida por Jean-Pierre Terrail (1990), para representar os filhos da classe operária francesa que ascenderam socialmente por meio da educação superior, nas décadas de 1970 e 1980. O principal objetivo do autor é discutir os rumos da classe trabalhadora francesa, em vista das mudanças produtivas, culturais e sociais, ocorridas no pós-68. A partir desta conjuntura, os efeitos da crescente individualização são interpretados através de uma chave um tanto negativa, que busca colocar tal processo em contraposição à viabilidade de um projeto comum para os trabalhadores franceses. Desta forma, o estudo de caso de 23 biografias de profissionais de nível superior, oriundos dos meios populares, é abordado a partir de uma construção teórica que valoriza a descontinuidade entre o atual estilo de vida desses indivíduos e o de seu meio de origem. A complexidade dos casos náo deixa de ser, todavia, contemplada pela descrição de Terrail (1990), que identifica diferentes formas de engajamento das famílias investigadas ante a escolarização. Os sentidos desse engajamento podem tanto nos revelar uma autodepreciação da condição operária, como, em outros casos, apontar para uma valorização da mesma condiçãa, nutrida como projeto político pela esquerda proletária.

Com a preocupação de demonstrar os efeitos desmobilizadores da individualização nas classes proletárias, estas interessantes nuanças são rebaixadas em favor do argumento geral da obra, que preza por uma ideia de ruptura e de descontinuidade entre a cultura dos trabalhadores franceses de outrora $\mathrm{e}$ aquela vigente no período investigado. Portanto, o trânsfuga de classe de Terrail, retratado em meio à crise do Estado de bem-estar social e o insurgente neoliberalismo, constrói o seu projeto de ascensão por meio da ruptura com sua cultura de origem: "Prosseguindo seus estudos, ele realiza o desejo dos pais, embora fazendo de tudo para náo ser o que eles são: amar e trair inevitavelmente $[. . .]^{1}$ ». (Terrail, 1990, p. 249).

A ênfase no choque cultural ocorrido entre a origem popular e o destino de classe média, ou alta, pela via da educação superior, é dada sobretudo nos trabalhos em que a socialização do indivíduo que ascende é demonstrada ou assumida como uniforme. No caso, a pressuposição de uniformidade ocorre quando se entende que o indivíduo, durante seu desenvolvimento, foi exposto quase exclusivamente a um único repertório cultural. Os exemplos, já citados, podem ser representados pelo proletariado inglês do início do século XX de Hoggart, caracterizado por sua cultura sólida e resignada, ou pelos trabalhadores franceses de Terrail, marcados por um engajamento coletivo acentuado pela forte solidariedade de classe. No Brasil, considerando os níveis de desigualdade social e a seletividade do sistema de ensino superior, a imagem do trânsfuga de classe aparece, em muitos trabalhos, como aquela que melhor descreve a trajetória de ascensão dos sujeitos investigados - ainda que tal representação apareça nuançada ou mesmo questionada em algumas contribuiçóes.

$\mathrm{Na}$ obra de Bourdieu, o conceito de habitus, "princípio unificador e gerador das práticas", representa o elemento subjetivo do processo de incorporação das disposições próprias da condição de classe da qual cada um de nós é originário. (Bourdieu, 2007, 2001; Peters, 2015). O repertório de ações que o ator incorpora forneceria um mapa que orienta o seu posicionamento no espaço público. Dos gestos 
às escolhas alimentares, o habitus incorporado é, dessa maneira, uma espécie de manual que coloca a cada indivíduo as facilidades e dificuldades que o seu repertorio de ações encontrará para ser ativado na vida em sociedade.

O repertório incorporado é um conjunto durável de disposições extremamente propenso à reprodução. A performance do ator é ativada tacitamente, por meio do reconhecimento de estruturas de ação familiares a seu repertório. Programados para agir de determinada forma, os indivíduos tendem a rejeitar situaçóes em que não encontram a correspondência entre o habitus incorporado e as estruturas objetivas do campo. A engrenagem, que funciona por perfeita correspondência, defronta-se, obviamente, com situaçóes em que dela se requer outro modus operandi. Tais situaçóes provocam desgastes e tendem a revelar a profunda falta de naturalidade do agir de quem não está acostumado com aquela configuração situacional. A obra A Distinção: crítica social do julgamento (Bourdieu, 2011) é um exemplo eloquente da aplicação desta proposta teórico-metodológica. Através do estudo minucioso de práticas culturais de franceses de distintas classes sociais, Bourdieu argumenta sobre a enorme correspondência entre escolaridade (alta e baixa) e renda (alta e baixa), de um lado, e determinadas preferências culturais manifestadas na pesquisa, de outro lado. A obsessão pela equivalência entre o habitus incorporado e as práticas culturais esconde, por sua vez, a flagrante heterogeneidade de práticas que dão o tom predominante da maioria dos perfis estudados. ${ }^{2}$

A socialização primária, aquela vivida essencialmente no espaço da família, é o processo pelo qual o sistema de disposiçóes, próprio à classe de origem, será incorporado pelo indivíduo, deflagrando práticas semelhantes àquelas mantidas pelos pares da classe. A socialização secundária, vivida na escola e na vizinhança, tenderia a reforçar, nos ambientes populares, a homogeneidade dessas práticas, por meio da convivência quase exclusiva com pessoas do mesmo perfil social. Seguindo a lógica bourdieusiana, a homologia entre habitus e campo, que seria produto justamente da tendência à reprodução das práticas incorporadas, levaria o indivíduo a um destino de classe esperado. Os herdeiros, através de uma atração potente e silenciosa, ocupam os cargos para os quais parecem naturalmente vocacionados, seguindo, dessa forma, a trajetória modal de seu grupo. Em outras palavras, a reprodução social, que promove o encontro entre habitus e estrutura objetiva, é o que explica a enorme probabilidade de filhos de profissionais qualificados tornarem-se profissionais qualificados; ou ainda, de filhos de operários tornarem-se operários.

A correspondência entre disposiçóes e estrutura objetiva nunca é perfeita, e o influente sociólogo francês reconhecia, e trabalhava, com trajetórias que desviavam das expectativas modais da classe. Os casos extremos chamavam a sua atenção, pois as fraturas ocasionadas no estoque de disposições, incorporado por experiências como a imigração e a mobilidade ascendente, formavam um novo tipo de "habitus clivado, destroçado, ostentando sob a forma de tensôes e contradiçóes a marca das condiçôes de formação contraditórias de que são o produto". (Bourdieu, 2001, p.79).

O habitus clivado reflete o repertório de ação do trânsfuga de classe, praticamente a única possibilidade em que Bourdieu lida com uma socialização heterogênea, pela qual convivem, no mesmo indivíduo, distintas - e até contraditórias - propensóes para agir. Com base no material empírico mobilizado na presente discussão, a adoção da perspectiva do autor nos levaria a: a) ignorar as variaçôes do tipo de disposiçôes para agir, interpretar e sentir, às quais os entrevistados pesquisados foram expostos desde a infância; e b) assumir a sua experiência social, como um relicário de situações dramáticas, demandantes de enorme esforço pessoal para dirimir os conflitos por elas ocasionados.

A exposição dos dados, articulada à revisão crítica desta tradição teórica, buscará uma alternativa interpretativa que contemple os diferentes repertórios culturais aos quais o indivíduo está exposto, sem as marcas negativas da deserção ou da culpa. Evita-se, dessa forma, interpretar a mobilidade educacional investigada, como um movimento amplo realizado entre posições extremas da escala social, o que, na maioria dos casos, não ocorre. De outro lado, questiona-se a conduta social atribuída ao trânsfuga de classe, que, ao entrar em contato com um ambiente onde todas as referências lhe seriam apresentadas 
como inéditas e disruptivas, viveria um eterno transtorno. Obviamente, não se trata da defesa de uma abordagem que elimine o conflito ou qualquer dilema próprio desse processo; mas sim, da adoção de uma perspectiva teórica que assuma a socialização, em especial em grandes metrópoles, como o Rio de Janeiro, como uma ação exposta desde cedo à influência de repertórios plurais, que são internalizados pelos indivíduos com intensidades variáveis (Lahire, 2002; 2006). Tal perspectiva reconheceria neles capacidades de ação diversificadas, considerando-os, ainda, como atores competentes para a leitura de diferentes contextos. O material empírico analisado é valoroso, portanto, para tal discussão, por apresentar diferentes maneiras de agir e pensar de pessoas com origem socioeconômica muito semelhante.

\section{Apresentação dos dados e da estratégia metodológica}

A discussão apresentada neste artigo é derivada da análise de um conjunto de entrevistas realizadas entre os anos de 2014-2015, a partir de uma pesquisa mais ampla, que investigava os sentidos da diplomação de ensino superior para a primeira geração de formados na família. Para compor este corpus, foram estabelecidos os seguintes critérios: ser a primeira pessoa graduada da família, ter pais que houvessem completado no máximo o ensino secundário, e, quando integrantes da população economicamente ativa, terem exercido ofícios predominantemente manuais e com baixa exigência de qualificação. Estas características foram definidas com o objetivo de indicar a origem popular do público-alvo da pesquisa. Logo, o pertencimento às camadas populares foi derivado das informaçóes sobre a escolaridade e a ocupação dos pais dos entrevistados.

A prioridade era encontrar indivíduos na faixa etária dos trinta anos, que houvessem frequentado o sistema de ensino superior a partir dos anos 2000, período marcado pelo fortalecimento da expansão do ensino superior no país, e pela implantação de medidas que visavam à democratização desse acesso (Feres Junior; Daflon; Campos, 2013). Associado ao critério da formatura, os candidatos, cujas trajetórias obedeciam às condiçôes do objeto de análise, já deveriam ser atuantes no mercado de trabalho.
Embora as características acima definidas representassem critérios com restrita flexibilidade, as variações no perfil aconteceram e foram extremamente profícuas para a questão proposta. Consonante com Small (2010), a seleçáo dos entrevistados buscou replicar casos semelhantes entre si, mas também flexibilizar os parâmetros estabelecidos, visando compreender com maior acuidade os fatores que influenciavam $\mathrm{e}$ modificavam as percepçóes dos atores. As condições socioeconômicas das famílias foram classificadas em uma escala que parte de situaçóes mais precárias a outras que flertam com a fronteira de uma classe média baixa. Narrativas semelhantes, entre indivíduos com padrão de vida distintos, demonstram a atuação de outros condicionantes, para além do fator renda, na conformação de planos educacionais longevos. Apesar de nenhum entrevistado ter questionado o seu pertencimento de origem às fraçóes populares, a partir dos relatos obtidos é possível também estudar como as diferenças, quanto ao orçamento familiar, impactaram o horizonte de expectativas desses indivíduos e, consequentemente, suas decisões.

A partir de critérios definidos, a procura dos casos foi realizada por meio de contatos pessoais da pesquisadora e, subsequentemente, por indicaçóes dos próprios entrevistados, seguindo um modelo conhecido como "bola de neve" (Alberti, 2004), no qual o investigado indica ao pesquisador possíveis candidatos ao estudo. No total, foram realizadas 29 entrevistas, sendo 25 analisadas. A temporalidade da feitura das últimas entrevistas impossibilitou a sua inclusão destas no corpus analisado, obedecendo aos critérios de transcrição integral do conteúdo e de sua posterior classificação. A exclusão destas entrevistas do conjunto analisado não representou, todavia, prejuízo à compreensão do problema colocado, pois com a conclusão da maior parte das entrevistas já havia sido alcançado o ponto de saturação substantiva, momento em que se percebe a repetição de temas e o acréscimo pequeno de novas dimensóes à questáo de pesquisa proposta (Bertaux, 1980).

As entrevistas seguiram um roteiro aberto, semidiretivo, cuja intenção estava no estímulo à produçâo de relatos informados e detalhados sobre as questôes colocadas. Os locais de encontro foram definidos pelos entrevistados, e sua duração não foi 
previamente estabelecida, mas sim condicionada à disponibilidade de cada indivíduo e ao gosto que tiveram pelo encontro pouco usual a que estavam dedicando o seu tempo. Todos os relatos foram transcritos integralmente e codificados a partir de temas amplos: (expressóes do sentido do diploma; marcaçôes de fronteiras; percepçóes sobre a sociabilidade e questóes de gênero).

Os relatos foram tratados e analisados, assumindo-se a perspectiva de que tais narrativas não são apenas representações, mas construções de mundo. Ou seja, abandona-se a perspectiva do uso da narrativa como representação limitada às idiossincrasias do indivíduo isolado, em favor de um olhar que a toma como condição ontológica da vida social. (Ricouer, 1995, 1980; Somers, 1994). Contar uma história envolve a exposição de fatos e afetos, que são percebidos pelo narrador como elementos adequados para formar um conjunto coerente, capaz de transmitir os sentidos desejados. $\mathrm{O}$ ato de narrar expóe, desse modo, elementos valiosos para melhor compreender o sujeito que narra e o contexto no qual ele se insere. Os entrevistados foram induzidos a relatar sua trajetória, respondendo a questóes que buscavam compreender, dentre outros aspectos: o processo de escolarização desde os primeiros anos; a relação da família com a educação; a importância dos laços sociais (vínculos fraternais, parentais e profissionais); as vivências de trabalho e lazer na infância e adolescência; a entrada na universidade; a experiência universitária; a formatura e a entrada no mercado de trabalho; e, por fim, o sentido da formação universitária para cada um deles.

O grupo de entrevistados é composto por 13 mulheres e 12 homens, que, em média, têm 30 anos de idade. Todos realizaram sua formação superior no estado do Rio de Janeiro, local onde as entrevistas foram realizadas. A descrição do grupo investigado está disponível na Tabela 1 ao final do texto.

\section{Limites do conceito de trânsfuga de classe}

Como apresentado na sessão anterior, o grupo de entrevistados foi selecionado a partir de critérios de pertencimento de classe que possibilitassem o seu enquadramento na categoria "popular". Dessa forma, o pertencimento à classe popular foi definido a partir da escolarização e ocupação de seus pais. Esse grupo, pretensamente homogêneo, ofereceu, contudo, um rico estudo de caso sobre os diferentes tipos de socialização encontrados nas camadas populares. Dessa forma, a caracterização da trajetória de ascensão dos entrevistados, a partir de rótulos extremos, como o de trânsfuga de classe, nos levaria à construção de tipos ideais, desconectados com a realidade. Com intensidades distintas, grande parte dos entrevistados relatou o contato com pessoas, lugares e atividades que lhes apresentavam novos mundos e, portanto, outras maneiras de encarar a própria vida.

Comumentemente, a socialização é apresentada como um processo dividido em duas etapas. A etapa vivida essencialmente na família, que seria a socialização primária, e as etapas subsequentes, nas quais o indivíduo é exposto a influências de grupos externos, como a escola, a vizinhança e o grupo religioso, ou seja, a socialização secundária. Contudo, assumir a socialização primária como um momento no qual é transmitido ao indivíduo um conjunto uniforme de disposições constitui um equívoco, que essa separação analítica do processo provoca, segundo Lahire (2002, 2006). Há duas formas de questionar a homogeneidade dessa transmissão cultural da família aos seus descendentes. Primeiro, desde muito cedo as crianças já estariam expostas ao mundo externo, através do contato com babás, creches, cuidadoras, entre outros. Segundo, é preciso considerar o próprio espaço familiar como fornecedor de princípios contraditórios de referências para sentir, classificar e agir no mundo. A família, mesmo que de extrema importância para a formação do indivíduo, raramente consegue efetivar um plano total de transmissão de valores e práticas aos seus descendentes. Até porque a ideia da existência de um repertório uniforme é difícil de sustentar, mesmo considerando-se apenas o núcleo familiar. As narrativas dos entrevistados revelaram tal fato, quando, por exemplo, descreveram os papéis de gênero assumidos pelo pai e pela mãe. Em inúmeros relatos, a saída da mãe do mercado de trabalho, por conta do casamento ou da gravidez, foi exposta com pesar. Mesmo crescendo em um ambiente em que o papel de provedor estava vinculado ao homem, algumas entrevistadas foram afetadas por um desejo de conquistar a própria independência e seguir uma 
carreira. Em alguns casos, o incentivo à independência financeira e a ênfase na carreira partiram da própria mãe, que carregava as marcas da insatisfação com os rumos de sua vida profissional. Já, em outros casos, a percepção negativa das entrevistadas sobre o destino ocupacional materno parece servir de um contraexemplo poderoso. ${ }^{3}$

Os dados, apresentados abaixo, pretendem embasar a discussão acima, contribuindo para a complexificação do modelo de socialização e suas consequências usualmente atribuídas às camadas populares. Repertórios de ação, ora mais homogêneos, ora mais heterogêneos em relação à classe de origem, devem ser assumidos como probabilidade, e não como atributos determinados. Questiona-se, a partir da percepção dos próprios entrevistados, a aplicação do rótulo de trânsfuga de classe às suas trajetórias. Primeiramente, podemos problematizar a caracterização da saída dos estratos populares rumo ao estrato médio da população, em termos da inserção ocupacional, através de um conceito que implica movimentos de grande amplitude, como seria o caso da ascensão social de quem parte dos estratos mais baixos rumo ao topo da pirâmide ocupacional. Em segundo lugar, ponto central desta discussão, afirma-se que construir a imagem de deserção, inadaptação e sofrimento constante impóe barreiras ao entendimento da experiência de jovens de camadas populares no ensino superior.

São dois os conjuntos de evidências que pretendem exemplificar, através da memória dos entrevistados, como estes "decodificaram" o mundo da universidade. Primeiramente, merecem destaque as experiências pregressas, que os apresentaram a outros ambientes sociais. Estas vivências certamente não foram antídotos para todas as situaçôes de dificuldade enfrentadas, mas serviram de recurso importante naquele período. ${ }^{4}$ Já o segundo bloco traz exemplos de como eles se percebem como portadores de distintos modos de agir e mostraram-se hábeis para acionar diferentes linguagens, quando necessário, sem que esse comportamento seja lido como inautêntico.

Busca-se, através dos dados, reforçar o argumento construído sobre as consequências dos pressupostos assumidos, quando se usa o conceito de trânsfuga de classe para interpretar casos de longevidade educacional nas camadas populares. Modelos distintos de socialização são potencialmente observáveis em todos os estratos sociais. Considerar que indivíduos oriundos dos meios populares possuam um único repertório de ação é uma hipótese arriscada em um contexto, no qual "o pluralismo interno do ator é a regra, e não a exceção” (Lahire, 2002). Tal concepção é, segundo as observaçóes da presente pesquisa, a que melhor descreve o tipo de socialização à qual parte dos investigados foram submetidos durante sua infância e adolescência. Portanto, descrever a mobilidade educacional observada, como um movimento exclusivamente cercado de choques culturais e desajustes, seria ignorar que, mesmo de forma subalterna, esses indivíduos já possuíam referências desse ambiente, de modo que a convivência com distintos repertórios de ação não deve ser tomada como necessária fonte de instabilidade emocional ou deserção.

\section{Socialização Plural}

Em alguns momentos, ao ser questionado sobre sua experiência escolar, infância e adolescência, E20 associou as oportunidades que teve à configuração particular de seu ambiente doméstico, considerado por ele como propício a descobertas. O pai do entrevistado aposentou-se por invalidez, aos 36 anos de idade, do serviço de limpeza urbana que realizava no município de Nova Iguaçu. O fato, porém, foi descrito na entrevista como uma oportunidade, uma vez que o convívio entre o entrevistado e seu pai aumentou depois desse evento. O trabalho de diarista da mãe também foi apresentado como fonte de benefícios extras, como os livros e revistas que ela trazia de seu serviço. Foi através do material didático do curso de inglês CCAA, obtido pela mãe em seu local de trabalho, que ele iniciou os seus estudos de língua estrangeira.

Era um ambiente muito propício, eu diria. Como o meu pai era aposentado, ele tinha um salário um pouco melhor do que a minha mãe. Ele sempre me levava pra fora de Nova Iguaçu. A minha infância era "vamos acampar em Copacabana, Cristo redentor", enquanto muitas crianças não têm esse acesso. (E20) 
E20 também viu o seu horizonte expandir, através dos vários cursos de teatro que frequentou, desde cedo. "Entáo, eu comecei fazendo curso de modelo e manequim, teatro, numa academia perto de casa em Nova Iguaçu. Aquilo foi crescendo e, então, eu comecei a fazer várias atividades e foram surgindo contatos, me inscrevi em agências..." (E20). As experiências da infância e adolescência marcaram o entrevistado, de modo que quando perguntado sobre sua adaptação ao meio universitário, ele vinculou a facilidade que teve a tais experiências pregressas:

Dificuldade eu não tive, mas as pessoas falavam das escolas que elas estavam vindo e esse foi o meu primeiro impacto: "nossa, eu sou o único que estou aqui e que tenho um histórico mais simples, de ter dificuldades com educação". Esse foi o meu primeiro desafio. Mas isso sempre, pelo teatro, fui uma pessoa muito tranquila. Navegar na PUC, pra mim, foi muito fácil, porque, como eu estudei no Tablado, que é uma escola tradicional, bem famosa, eu já tinha amizades muito grandes, muito fortes, com muitas pessoas que não se importavam com a minha origem: "ah, você veio de Nova Iguaçu. A gente estuda na mesma escola”. Então, eu navegava na PUC já conhecendo porque metade dos meus amigos do Tablado fazem Comunicação na PUC. Então, eu caminhava pela PUC e: "oi", "oi". Eu conhecia muita gente. (E20)

Durante a sua infância e adolescência, E4 conviveu quase exclusivamente com os amigos da escola, que eram também os amigos da vizinhança. Morador da Rocinha, o trânsito pelos bairros nobres da Zona Sul do Rio de Janeiro era corriqueiro e necessário, para acessar as escolas de ensino fundamental e médio. A localização privilegiada da Rocinha, no espaço urbano do Rio de Janeiro, fez com que o entrevistado acessasse com maior facilidade espaços, como a praia e o Jardim Botânico. A frequência sempre era feita, contudo, na companhia dos amigos da comunidade onde vivia, que também eram os amigos da escola. Quando perguntado sobre cursos ou outro tipo de atividade, E4 relatou a oferta baixíssima, na sua época, de formaçóes extracurriculares, lúdicas, ofertadas por ONGs, ou outros atores na comunidade: "Raríssimo.
Hoje eu sempre brinco que, desde adolescente, eu gostava de fotografia. Eu não tinha acesso à Internet e eu queria fotografar, aprender, mas nunca tive dinheiro para comprar uma máquina" (E4). $\mathrm{O}$ entrevistado saiu do ensino médio sem pensar em universidade, e, inclusive, rejeitava a ideia, à época. Seu desejo era trabalhar e ter dinheiro para sustentar as necessidades da juventude, assim como ajudar em casa. Nesse período, ele conseguiu um emprego em uma copiadora, localizada na Pontifícia Universidade Católica. O irmão já trabalhava no local e a proximidade de sua casa era um diferencial. Dois fatores são listados por E4, para definir sua entrada na universidade. Primeiro, ele estava na PUC e percebia que, se não estudasse, ficaria estagnado. "Fiz para Ciências Sociais. Porque eu já trabalhava na PUC, apesar da xerox não ser da PUC, ela era privada. Aí, eu pensei 'pô, eu acho que dá para estudar aquii”' (E4). Além do emprego, o apoio de sua namorada, e atual companheira, foi também fundamental. Incentivadora do plano do namorado, foi através do conhecimento dela que ele soube da possibilidade de ser bolsista integral na instituição: "A Maria, minha esposa, toca nesse convento. Um convento que tem na Gávea, próximo da PUC. O reitor da PUC celebrava missa lá, às vezes. E ela, por coincidência, pelo convívio católico, ela conheceu o responsável pela vice-reitoria comunitária..." (E4). ${ }^{5}$ A conciliação entre trabalho e estudo, e o encontro com pessoas com padróes de consumo e culturais totalmente diferentes dos que ele tinha foram apontados como questóes impostas à sua vivência universitária.

Por exemplo, cursos de Engenharia, de Administração. Quando fazíamos trabalho em grupo, começava uma conversa na roda sobre viagens, as pessoas da minha idade, ou mais novas, já tinham ido para Paris, Nova Iorque, Espanha, todos os países que você possa imaginar, eles já tinham visitado. E eu não tinha assunto nenhum, porque eu não tinha visitado nenhum. Não sabia nada. (E4)

Entretanto, em sua maioria, os estudantes de Ciências Sociais eram bolsistas e tinham trajetórias de vida semelhantes à do entrevistado. As dificuldades de adaptação e de sobrevivência financeira, no ambiente 
universitário, foram amenizadas pela rede de amizades que ele formou.

A universidade não me deu só conteúdo, ela me deu mais maturidade para ver as coisas de uma maneira diferente. De pensar o pertencimento ao espaço público... Eu escuto coisas que não escutava de músicas, por influência da minha mulher. Eu comecei a gostar de outras coisas, também. Quando você é novo, vem de espaços populares, há um receio de frequentar alguns espaços. Você pensa 'ah, isso não é para mim'. E as pessoas que estão no seu entorno, sem querer, te incentivam a pensar que aquilo não é para você. Hoje, eu ando praticamente em qualquer lugar. Eu não me sinto intimidado de entrar em lugar algum. (E4)

Realizar o ensino médio em uma escola da rede federal, cujo ambiente organizacional se assemelha ao de uma instituição universitária, foi uma oportunidade decisiva, segundo E11, em sua trajetória. Natural de Duque de Caxias, o entrevistado ressalta como sua ideia de sucesso, que, antes do ensino médio, consistia em seguir a carreira militar, foi se modificando com o conhecimento de novas possibilidades. E11 toma conhecimento de novas perspectivas, que serão importantes para a decisão pelo curso de Geografia.

Eu tinha um pouco de preocupação de sofrer preconceito. Eu pensava que iria para São Cristóvão, mas, ao mesmo tempo, puxava carroça em Santa Lúcia. Eu fiquei um pouco preocupado de não ser aceito, alguma coisa... Cheguei e percebi que era um ambiente muito plural, com gente de todos os cantos. Eu acabei colando com uma galera, que hoje eu percebo que não era uma galera tão massa. Hoje, eu escolheria outra galera. Eu escolheria a galera do grêmio estudantil. A galera que eu escolhi era... Logo, eu colei com um cara que foi muito meu parceiro, mas depois minha relação com ele ficou mais difícil. O nome dele era Augusto, ele também era negro, tinha poucos, tinha até alguns não era tão absurdo, mas é claro que éramos minoria. [...] Tinha uma galera que se juntava, não em torno da gente, mas que tinha afinidade. Nós saíamos muito, íamos para cinemas, para a praia. Nós assistíamos à aula e depois saíamos para fazer alguma coisa: praia, para o CCBB. $\mathrm{Na}$ verdade, para o $\mathrm{CCBB}$ eu nem ia tanto com eles. Mas, é nesse momento que eu vou conhecer o centro do Rio. Nós íamos muito ao cinema, meio de semana, era baratíssimo, jogávamos carta e ping pong. [...] Nós falávamos mal de quem era do grêmio. E eu pensava que o grêmio era legal, mas não colocava isso naquele momento. Quando acabou, eu percebi o quanto eu tinha limitado certas visóes do mundo que eu queria desenvolver, por exemplo, sobre desigualdade, sobre as diferenças dentro da sociedade, que eu não expressei porque não tinha espaço dentro daquele grupo. A ideia [nesse grupo] era se formar, militar ou engenheiro, se dar bem e estar do lado dos vencedores. (E11)

A menina negra nascida e criada na Rocinha sempre fora incentivada a ganhar o mundo pelos pais. Essa é a memória que E19 tem de sua criação. Buscar novas experiências foi um comportamento aprendido por ela, desde cedo. Esse aprendizado se deve, em grande parte, às iniciativas de seus pais, que sempre estavam atentos às oportunidades de cursos e de vivências, fora do entorno imediato da família. Durante sua infância e adolescência, ela fez balé, dança afro, teatro, natação, a maioria em cursos gratuitos, ou cursados através de bolsas e descontos. "Inglês, por exemplo, na época, eles não tinham dinheiro, mas o meu pai foi como um louco pedir bolsa na Oxford, que era um curso em Copacabana, um curso que só estudava quem tinha grana" (E19).

Cursos, pessoas conhecidas, experiências de trabalho, a condição de moradia na cidade do Rio de Janeiro são exemplos de vivências e aprendizados que foram citados pelos entrevistados como úteis à sua vida como universitários. Seja para escolher o curso, para navegar pelos espaços das instituiçóes superiores, ou para melhor aproveitar o período da graduação. Obviamente, o flerte com o mundo de classe média não evitou a nenhum deles as dificuldades enfrentadas por quem não possui recursos familiares para se sustentar neste ambiente, além do preconceito racial relatado pelos entrevistados negros. Contudo, 
imaginar um ser completamente desajustado no ambiente universitário não parece descrever bem o movimento que estes jovens adultos traçaram, no ensino superior. Para tanto, seria necessário ignorar os diferentes vocabulários que eles acumularam até a entrada na universidade, e tratar a sua experiência popular como unívoca.

\section{Sujeitos desenraizados?}

As trajetórias analisadas nos sugerem a incorporação, em diferentes etapas da vida dos entrevistados, de disposiçôes distintas do que poderíamos classificar como próprias da origem popular. Em alguns casos, logo cedo, o contato com estilos de vida estranhos aos do convívio familiar e da vizinhança era uma realidade, que muitos pontuaram, em suas narrativas, como algo positivo para as suas vidas. Para outros, o vestibular e a entrada na universidade foram identificados como momentos importantes, em que começaram a lidar com um mundo diverso daquele em que estavam acostumados a conviver. Nessas condições, todos possuem um repertório de disposiçóes heterogêneo, resultado da socialização mais ou menos diversa a que foram expostos. A convivência com tal pluralidade não os leva necessariamente ao conflito identitário e às crises de pertencimento. Como afirma Lahire (2006), o indivíduo plural é competente para adaptar esse repertório, de acordo com o contexto em que está inserido. Ou seja, ele consegue reconhecer as situaçôes que lhe demandam tal ou qual ação ou comportamento, embora não consiga evitar situaçóes conflituosas, em que não controla ou não entende o repertório compartilhado. E13, por exemplo, relata os diferentes tipos de linguagem que utiliza para se comunicar nos ambientes que frequenta: "Até para falar português, falar o português corretamente, de acordo com o que a língua exige. Não que eu vá falar um português correto toda vez que eu estiver falando com um amigo da Rocinha” (E13). Essa competência não pode ser lida, contudo, como reflexo de um agir inautêntico, a que os egressos do meio popular estariam submetidos por sua condição de trânsfugas de classe (LAHIRE, 2004).

Ampliar a rede de contatos, circular em novos espaços, modificar antigos hábitos significou, para parte dos entrevistados, uma constante adaptação do seu agir nos diferentes ambientes sociais pelos quais transitavam. Para muitos, é difícil conviver com os velhos amigos de infância, que não obtiveram o mesmo sucesso educacional que eles. Parte dessa rede de contatos foi perdida por alguns, mas os que mantiveram os velhos camaradas relataram que recorrem às velhas linguagens e hábitos comuns, para o bom curso da interação.

P - Por que é muito diferente da que você vive atualmente?

E18 - Eu não sei se tem a ver com o nível de escolaridade, pode ser que sim. Acho que tem a condição... talvez no sentido de... eu sinto dificuldade, porque me vejo um 'top' acima. Pode até ser estranho, mas... eu tenho um top acima, sou superior... sabe? A conversa, às vezes, é meio estranha. "Ah, meu Deus, tem que falar disso, porque não posso falar de outra coisa”. É essa a dificuldade.

$\mathrm{P}$ - Tem algum exemplo disso que você tá falando? Desse desnível, no sentido de vir com um assunto e as pessoas não conseguirem captar.

E18 - Isso, é sempre o contrário. Teve um caso que eu comecei a falar de engenharia, sobre curso... e ele vinha com a nostalgia: "lembra, naquela época...”. E eu sempre entrava na conversa deles. Não que essa nostalgia seja nesse sentido, porque a única conversa que eu tenho clara, objetiva com eles é sobre isso, de lembrar do que ocorreu. Acho que não tem uma exemplificação, mas acho que eu mesmo moldei na minha cabeça, sobre alguma coisa passada: "ai, como era bom...”, "como está a sua família?”, “o que você está fazendo?”, a esse nível. Os outros, que cresceram junto comigo, tipo o filho da patroa da minha mãe, que hoje é médico, aí já é outra questão. É outra mentalidade, outra conversa. Mas, às vezes, eu sinto dificuldade nesse sentido. Aí, eu recorro à nostalgia.

E12, por exemplo, mantém contato frequente com os amigos de infância. Convívio que, segundo 
ele, é estimulado pela proximidade geográfica que os vincula, uma vez que ele continua residindo no mesmo local onde cresceu. Mesmo que náo perceba nenhuma grande dificuldade nesta relação, sente que ocorreram mudanças depois de sua entrada e saída da faculdade. Muitos amigos de infância o procuram para pedir conselhos sobre a vida, ainda que ele não se veja confortável nessa posição.

Acho que eles acabam me vendo de forma diferente, por eu ter me formado, porque muitos deles nem concluíram o estudo todo, completo. Eu, por eu ter formado, ter conseguido dar alguns passos à frente, eles que me veem de forma diferente, mas eu mesmo enxergo todo mundo igual. (E12)

Muitos relataram possuir novos hábitos, que náo são compartilhados com os amigos de origem e a família. O alcance educacional e profissional dos velhos contatos é colocado como explicação para o não compartilhamento desse novo estilo de vida. Restriçôes econômicas, por outro lado, também são tidas como barreiras para a conciliação dos dois círculos sociais que passam a frequentar.

Não se encontram muito, porque a minha família... eu sempre estou com a minha família, são pessoas especiais, mas saio mais com a minha mãe, com a minha sobrinha, com a minha irmã... Eu gosto de ir ao teatro, mas eu sei que ir ao teatro é caro e todas as minhas tias são diaristas, elas não podem levar todo mundo ao teatro. Às vezes, eu tenho dinheiro pra ir ao cinema e posso levar, posso pagar pra minha mãe, pra minha sobrinha e pra minha irmã, mas eu não posso pagar pra toda minha família. Eu sei que são atividades caras, que nem todo mundo consegue fazer, mas eu sempre estou em casa, continuo me relacionando, é a mesma coisa. Visito a casa de todo mundo, todo mundo visita a minha. (E20)

A imagem que os entrevistados fazem de si mesmos aponta para sujeitos que transitam entre diversos ambientes e são hábeis em perceber demandas distintas de comportamento, em cada um deles. Há muitos relatos desgostosos pela perda de velhos contatos, ou pelas rusgas geradas quando da interação com pessoas do passado. A pecha de 'metido' é algo com que muitos convivem, na volta corriqueira à sociabilidade da infância. Contudo, narrativas de desenraizamento, culpa, deserçấo ou inadequação não estavam presentes nos casos analisados - evidência importante para questionarmos o quão é útil compreender as trajetórias educacionais longevas de indivíduos com origens populares a partir da influência, direta ou indireta, do rótulo de trânsfuga de classe. Se, por um lado, os entrevistados se ressentem de não serem bem compreendidos, ou náo encontrarem interlocutores entre os contatos de infância e juventude, eles também narram serem capazes de adaptar o seu repertório de ação, para prezar a boa convivência com o passado - o que indica uma açáo de equilíbrio entre os dois mundos, ao contrário da negação de parte importante do que os constituiu.

Tem a valorização do que você já vivenciava. Por exemplo, não que eu seja fă, um funk. Eu vou ouvir funk, sim. Náo adianta dizer que só o que vale é Chico Buarque. É a chamada música popular brasileira. Eu vou ouvir Chico Buarque; se eu tiver que ouvir um funk, eu vou ouvir, eu vou valorizar essa outra cultura. (E13)

\section{Consideraçóes Finais}

O conceito de trânsfuga de classe é frequentemente utilizado para descrever trajetórias de mobilidade de grande monta. O salto de média distância, mais modesto em comparaçáo à mobilidade de grande amplitude, sugere aos entrevistados um pertencimento à classe média, atravessado, contudo, por importantes referências da classe trabalhadora. Em relaçẫo às histórias de vida analisadas, o trânsito frequente entre tais pertencimentos de classe os expóe a enquadramentos, ora vindos do meio de origem, ora do meio de destino, assim como também os estimula a produzir classificaçōes para se movimentar em ambos os mundos. A pluralidade defendida, além de ser uma construção teórica amparada em uma formulação mais geral sobre a socialização contemporânea, está igualmente assentada na percepção que estas 
pessoas constroem sobre a própria vida. Por mais que tenham conquistado condiçóes econômicas e culturais que as diferenciam dos pares da origem, elas permanecem vinculados a eles, em parte pelas limitações materiais de sua ascensão, que não alçou nenhum dos estudados às posiçóes localizadas no topo do estrato populacional; mas também, em parte pelo modo como vivenciam os cenários mais facilmente franqueados pela sua ascensão.

Buscar o diploma de ensino superior revelouse uma tarefa desafiadora para estes jovens adultos. Com intensidades distintas, particulares a cada biografia, é pertinente afirmar que em todas as narrativas foram encontradas mençôes às dificuldades de ordem material e emocional que a entrada na faculdade ocasionou. Relatos estes, que vão ao encontro das experiências investigadas por pesquisadores da área. Entretanto, os obstáculos interpostos à jornada no ensino superior não foram o tom único dessas narrativas. Ao contrário, em muitas histórias de vida, as dificuldades receberam igual, ou menor atenção, em relação ao que os entrevistados descreveram como grandes oportunidades; ampliação de horizontes; aquisição de novos hábitos; entre outros fatores. Tal perspectiva positiva foi relacionada tanto à importância que conferiram à graduação em suas vidas, como às habilidades sociais pregressas que haviam adquirido e que lhes facilitaram o convívio nesse ambiente. Já munidos de referências das práticas sociais vinculadas à classe média, os choques culturais foram, para muitos deles, amenizados, ou mais bem administrados. Percepção esta que diverge daquelas de total desajuste no ambiente universitário e nos coloca outra perspectiva para a compreensão destas trajetórias.

Descrevê-las sob o forte estigma do trânsfuga de classe não é condizente com a imagem que os sujeitos fizeram de sua própria trajetória. Nos relatos, é possível identificar significativo número de mençôes positivas ao processo de entrada e formatura no nível superior, o que confronta com a versão exclusiva de uma experiência de enorme desgaste social, que implicaria apenas em um negativo impacto psicossocial na vida desses indivíduos. Os casos expostos no presente artigo reivindicam uma descrição de atores competentes para lerem contextos situacionais distintos e que se valem de um repertório diversificado de açóes para responder, e se movimentar, em cada um desses ambientes.

\section{Notas}

1 " Pousuivant ses études, il réalise le désir des parents, mais en faisant tout pour ne pas être ce qu'ils sont: aimer et trahir, inévitablement [...] ».

2 Revisões críticas aos argumentos defendidos por Bourdieu, em A Distinção, podem ser consultadas em Lahire (2006) e Brubaker (1985).

3 As desigualdades de gênero, observadas no sistema educacional, não são unidimensionais. As mulheres são mais numerosas do que os homens, nas instituiçôes escolares. Meninas das camadas populares alcançam maior escolaridade, do que seus pares do sexo masculino (Rosemberg, Madsen, 2011). Por outro lado, as mulheres estáo sobrerepresentadas em carreiras desvalorizadas no mercado, em consequência da evidente segmentação sexual das carreiras (Ribeiro \& Schlegel, 2015).

4 Embora os argumentos aqui defendidos sigam a revisão crítica de Lahire, acerca dos pressupostos de uniformidade do conceito de habitus, a ênfase da teoria bourdieusiana, no caráter agonístico da relação entre classes sociais, é, sem dúvida, um aspecto caro à análise de trajetórias de ascensão no contexto brasileiro, marcado por uma enorme desigualdade social (Wacquant, 2013). Os sujeitos investigados estiveram expostos a violências, em razão dos seus pertencimentos de classe, raça e gênero.

5 Todos os nomes mencionados nos trechos das entrevistas são fictícios.

\section{BIBLIOGRAFIA}

ALBERTI, Verena. (2004), Manual de História Oral. 2a edição, Rio de Janeiro, FGV.

ALMEIDA, Wilson Mesquita de. (2012), Ampliação do Acesso ao Ensino Superior Privado Lucrativo Brasileiro: um estudo sociológico com bolsistas do ProUni na cidade de Sáo Paulo. Tese de Doutorado em Sociologia. Faculdade de Filosofia, Letras e Ciências Humanas da Universidade de São Paulo, São Paulo.

BERTAUX, Daniel. (1980), "L'approche biographique: Sa validité méthodologique, ses potentialités ", Cabiers Internationaux de Sociologie, LXIX: 197-225. 
BOURDIEU, Pierre. (2007), O Poder Simbólico. 10ª edição, Rio de Janeiro, Bertrand Brasil.

BOURDIEU, Pierre. (2008), "As contradiçóes da herança", in P. Bourdieu (org), A miséria do mundo. $7^{\text {a }}$ edição, Petrópolis, Vozes, p. 587-593.

BOURDIEU, Pierre. (2011), A distinção. A crítica social do julgamento. $2^{\text {a }}$ edição, Porto Alegre, ZouK.

BOURDIEU, Pierre. Meditaçóes Pascalianas. (2001), Rio de Janeiro, Bertrand Brasil.

BRUBAKER, Rogers. (1985), "Rethinking classical theory: the sociological vision of Pierre Bourdieu", Theory and Society, 17:745-775.

CARVALHAES, Flávio; RIBEIRO, Carlos Antônio Costa; SOUZA, Pedro \& BARBOSA, Rogério. (2014), "Os impactos da geração de empregos sobre as desigualdades de renda: uma análise da década de 2000", Revista Brasileira de Ciências Sociais, 29, 85: 79-98.

FERES JUNIOR, João, DAFLON, Verônica Toste \& CAMPOS, Luiz Augusto. (2013), "Ações afirmativas raciais no ensino superior público brasileiro: um panorama analítico", Cadernos de Pesquisa, 43, 148: 302-327, jan./abr.

HOGGART, Richard. (1973), As utilizaçóes da cultura: aspectos da vida cultural da classe trabalhadora, com especiais referências a publicaçóes e divertimentos (2.v.) Lisboa, Editora Presença.

LAHIRE, Bernard. (2002), Homem plural: os determinantes da ação, Petrópolis, Vozes.

LAHIRE, Bernard. (2004), Retratos sociológicos: disposiçóes e variaçóes individuais, São Paulo, Editora Artmed.

LAHIRE, Bernard. (2006), A cultura dos indivíduos, São Paulo, Editora Artmed.

MARTUCCELLI, Danilo \& DE SINGLY, François. (2012), Sociologies de l'individu, Paris, Armand Colin.

NAUDET, Jules. (2007), « L'expérience de la mobilité sociale ascendante: les deux visages de la réussite sociale ». Notes \& Documents 2007-03, Sciences Po - OSC.

PETERS, Gabriel. (2015), Percursos na teoria das práticas sociais. Anthony Giddens e Pierre Bourdieu, São Paulo, Annablume.

PIOTTO, Débora Cristina. (2007), As exceçôes e suas regras: estudantes das camadas populares em uma universidade pública. Tese de Doutorado em
Psicologia. Instituto de Psicologia da Universidade de São Paulo, São Paulo.

PIOTTO, Débora Cristina. (2008), “Trajetórias escolares prolongadas nas camadas populares". Cadernos de Pesquisa, 38, 135: p.701-727.

PIOTTO, Débora Cristina. (2010), "Universitários de camadas populares em cursos de alta seletividade: aspectos subjetivos". Revista Brasileira de Orientação Profissional, 11, 2: p. 229-242.

PORTES, Écio Antônio. (1993), Trajetórias e estratégias escolares do universitário das camadas populares. Dissertaçáo de Mestrado em Educaçáo. Faculdade de Educação da Universidade Federal de Minas Gerais, Belo Horizonte.

PORTES, Écio Antônio. (2001), Trajetórias escolares e vida acadêmica do estudante pobre da UFMG: um estudo a partir de cinco casos. Tese de Doutorado em Educação. Faculdade de Educação da Universidade Federal de Minas Gerais, Belo Horizonte.

RIBEIRO, Carlos Antônio Costa \& SCHLEGEL, Rogério. (2015), "Estratificação horizontal da educação superior (1960-2010)”, in M. Arretche (org). Trajetórias das desigualdades: como o Brasil mudou nos últimos cinquenta anos. São Paulo, Editora UNESP, CEM.

RIBEIRO, Carlos Antônio Costa; MARSCHNER, Murilo \& CENEVIVA, Ricardo. (2015), Estratificação educacional entre jovens no Brasil: 1960 a 2010, in M. Arretche (org). Trajetórias das desigualdades: como o Brasil mudou nos últimos cinquenta anos. São Paulo, Editora UNESP, CEM.

SHAVIT, Yossi \& BLOSSFELD, Hans-Peter. (1991), Persisting Barrier: Changes in Educational Opportunities in Thirteen Countries. San Domenico (FI) Itália, Badia Fiesolana.

SILVA, Jailson de Souza. (2011), Por que uns e não outros? Caminhada de jovens pobres para a universidade, Rio de Janeiro, 7Letras.

TERRAIL, Jean-Paul. (1990), Destins ouvriers: la fin d'une classe?, Paris, Presse Universitaire de France.

VIANA, Maria José Braga. (2007), Longevidade escolar em famílias de camadas populares: algumas condiçôes de possibilidade. 1a. edição, Goiânia, UCG - Editora da Universidade Católica de Goiás.

WACQUANT, Loic. (2013), "Poder simbólico e fabricação de grupos. Como Bourdieu reformula a questão das classes", Novos Estudos CEBRAP, 96 , jun. 


\section{PARA ALÉM DO 'TRÂNSFUGA DE CLASSE': A SOCIALIZAÇÁO PLURAL EM NARRATIVAS DA PRIMEIRA GERAÇÁO DE FORMADOS NO ENSINO SUPERIOR}

\author{
Raquel Guilherme de Lima
}

Palavras-chave: primeira geração de formados; trânsfuga de classe; socializaçáo plural.

Trajetórias educacionais longevas de pessoas oriundas das camadas populares são objetos frequentes de reflexão sociológica. Pesquisas relevantes permitiram o avanço do conhecimento quanto às práticas que favorecem a emergência de alguns desses casos improváveis. O presente artigo aborda esta temática a partir de dados obtidos através de entrevistas em profundidade realizadas com 25 pessoas de origem popular, que representam a primeira geração de suas famílias a cursar o ensino superior. O objetivo é problematizar a imagem comumente atribuída a estas trajetórias, a qual usualmente ressalta o sofrimento, o sentimento de náo pertencimento e a ruptura cultural com o meio de origem. Argumenta-se, aqui, que a construção de tal imagem é influenciada pela mobilizaçáo do conceito de trânsfuga de classe. Por meio da análise empírica, questiona-se a aplicação de tal conceito em favor de interpretaçóes que considerem não apenas as diversas referências culturais a que estes indivíduos estão potencialmente sujeitos, mas também aquelas que os considerem atores sociais competentes para a leitura de diferentes contextos sociais.

\section{BEYOND THE "CLASS DEFECTOR": PLURAL SOCIALIZATION IN FIRST-GENERATION HIGHER EDUCATION STUDENT NARRATIVES}

Raquel Guilherme de Lima

Keywords: Brazilian first-generation higher education students; class defector; plural socialization.

Long-lived educational trajectories of people from lower classes are frequent objects of sociological reflection. Relevant research has allowed for knowledge advances concerning practices that favor the emergence of some of these unlikely cases. This article addresses this theme based on data obtained through in-depth interviews with 25 people presenting popular origins, who represent the first generation of their families to attend higher education. The aim is to problematize the image commonly attributed to these trajectories, which usually focuses on the suffering, the feeling of not belonging and the cultural rupture with the original working class environment. It is argued herein that the concept of such an image is influenced by the mobilization of the concept of class defector. Through an empirical analysis, this article criticizes the application of such a concept in favor of interpretations that consider not only the diverse cultural references to which these individuals are potentially subject to, but also those that consider them competent social actors for the reading of different social contexts.

\section{AU-DELÀ DU «TRANSFUGE DE CLASSE»: LA SOCIALISATION PLURIELLE DANS LES RÉCITS D'ÉTUDIANTS DE PREMIÈRE GÉNÉRATION}

Raquel Guilherme de Lima

Mots-clés: étudiants de première génération; transfuge de classe; socialisation plurielle.

La réussite scolaire de personnes de la classe ouvrière est un sujet de réflexion fréquent en sociologie. Et des recherches importantes ont permis de mieux connaître les pratiques favorisant l'ascension de certains de ces cas inattendus. Cet article analyse les données de 25 récits de personnes de la classe ouvrière brésilienne, les premiers de leur famille à avoir fréquenté un établissement d'enseignement supérieur. L'objectif est de remettre en question l'image habituellement associée à ces trajectoires: la plupart des études privilégie en effet la souffrance, le sentiment de non-appartenance et la rupture culturelle avec le milieu d'origine. Nous pensons que la construction d'une telle image est influencée par le concept de transfuge de classe. Sur la base de l'analyse empirique, le présent travail critique l'application de ce concept au détriment d'interprétations qui considèrent à la fois les différentes références culturelles susceptibles de concerner ces sujets, ainsi que celles qui les voient comme des acteurs sociaux capables de faire face à divers contextes sociaux. 


\section{Tabela 1}

Perfil dos entrevistados, sexo, idade, raça e graduação

\begin{tabular}{|c|c|c|c|c|}
\hline Entrevistado & Sexo & Idade & Raça* & Curso e Instituição \\
\hline E1 & $\mathrm{F}$ & 28 & Branca & Medicina (UNIRIO) \\
\hline E2 & $\mathrm{F}$ & 31 & Negra & Geografia (UFRJ) \\
\hline E3 & $\mathrm{M}$ & 28 & Negra & Serviço Social (UNISUAM) \\
\hline E4 & $\mathrm{M}$ & 36 & Negra & Ciências Sociais (PUC Rio) \\
\hline E5 & $\mathrm{F}$ & 24 & Branca & Ciências Sociais (UFRJ) \\
\hline E6 & $\mathrm{F}$ & 29 & Negra & Administração (PUC Rio) \\
\hline E7 & $\mathrm{M}$ & 29 & Negra & Serviço Social (PUC Rio) \\
\hline E8 & $\mathrm{F}$ & 37 & Negra & Matemática (UFRJ) \\
\hline E9 & $\mathrm{M}$ & 35 & Branco & Biologia (UFRRJ) \\
\hline E10 & $\mathrm{F}$ & 28 & Negra & Desenho Industrial (UERJ) \\
\hline E11 & $\mathrm{M}$ & 29 & Negra & Geografia (UERJ) \\
\hline E12 & $\mathrm{M}$ & 24 & Negra & Gestáo Ambiental (Estácio de Sá) \\
\hline E13 & $\mathrm{M}$ & 37 & Negra & Ciências Sociais (PUC Rio) \\
\hline E14 & M & 30 & Branca & Engenharia de Petróleo (PUC Rio) \\
\hline E15 & $\mathrm{F}$ & 28 & Branca & Pedagogia (PUC Rio) \\
\hline E16 & $\mathrm{M}$ & 31 & Negra & História (UFF) \\
\hline E17 & $\mathrm{F}$ & 32 & Branca & Letras (UCAM) \\
\hline E18 & $\mathrm{M}$ & 29 & Negra & Engenharia Elétrica (UFF) \\
\hline E19 & $\mathrm{F}$ & 31 & Negra & Comunicação Social e Psicologia (FACHA/UERJ) \\
\hline E20 & $\mathrm{M}$ & 27 & Negra & Relaçôes Internacionais (PUC Rio) \\
\hline E21 & $\mathrm{F}$ & 30 & Negra & Enfermagem (São Camilo) \\
\hline E22 & $\mathrm{M}$ & 35 & Negra & Serviço Social (PUC Rio) \\
\hline E23 & $\mathrm{F}$ & 30 & Negra & Administração e Ciências Contábeis (PUC Rio/UCAM) \\
\hline E24 & $\mathrm{F}$ & 33 & Negra & Serviço Social (PUC Rio) \\
\hline E25 & $\mathrm{F}$ & 28 & Negra & Enfermagem (UFF) \\
\hline
\end{tabular}

Fonte: elaboração própria, 2016. *A categoria racial “negra” é composta da junção de pretos e pardos. 